\title{
Self-management and family support in chronic diseases
}

\author{
Maria Isabel Peñarrieta , Florabel Flores-Barrios, Tranquilina Gutiérrez-Gómez, Socorro Piñones-Martínez, Eunice \\ Resendiz-Gonzalez, Luz maría Quintero-Valle \\ Universidad Autonoma de Tamaulipas, Mexico
}

Received: May 18, 2015

Accepted: August 5, 2015

Online Published: August 19, 2015

DOI: $10.5430 /$ jnep.v5n11p73

URL: http://dx.doi.org/10.5430/jnep.v5n11p73

\begin{abstract}
Objective: The propose was to evaluates the behavior of self-management in people with: diabetes, hypertension and cancer, and to analyze the relationship between self-management and family support.

Methods: This study has cross-sectional and correlational design. A convenience sample was used. The study was conducted at the Sanitary District Number 2 of Tampico, Tamaulipas, México. The sample consisted of 299 patients, the scale of selfmanagement in chronic illness: "Partners in Health Scale". The Kruskal-Wallis test, the Spearman and Kendall-Tau correlation were used for the analysis.

Results and Conclusions: The people of the study showed poor self-management. The statistical significance was found in the adherence dimension, being this difference in the group which was diagnosed with cancer, vs the diabetes and hypertension groups. The results of the family APGAR showed that $25 \%$ of the participants had moderate and severe family dysfunction; the results also show that this family support is not the only factor to consider in this behavior, although the statistical results were significant, yet this relationship is medium or low.
\end{abstract}

Key Words: Self-management, Family support, Chronic disease, Diabetes, Hypertension, Cancer

\section{INTRODUCTION}

Chronic non-communicable diseases (CND), such as cardiovascular diseases, diabetes, overweight and obesity, cancer and chronic lung diseases have achieved notoriety around the world. ${ }^{[1]}$ Eighty percent of the deaths caused by these diseases occur in middle and low income countries worldwide. $^{[2,3]}$ There is only a $20 \%$ adherence rate to treatment which results in negative health statistics and terrible consequences to the family, society and government. ${ }^{[4]} \mathrm{CND}$ are thus one of the biggest challenges the health system faces, and are the most common causes of premature disability resulting in high costs of treatment. ${ }^{[4]}$
Mexico is not excluded from this problem as CND also represent the major cause of morbidity and mortality due to chronic diseases and the increase in mortality rate in Mexico for the period 2000-2010. The results of diabetes $61 \%$, ischemic heart disease $50 \%$, neoplasia $20 \%$, circulatory problems $35 \%$, and strokes $18 \%$. The northern states of the country present the higher prevalence, among them, Tamaulipas. ${ }^{[5,6]}$

CND are illnesses that require attention throughout life and they require people to make major changes to adapt their lives to these conditions both for the people who suffer from the disease and his/her family. This situation leads to health

*Correspondence: Maria Isabel Peñarrieta; Email: PCORDOBA@uat.edu.mx; Address: Universidad Autonoma de Tamaulipas, Mexico. 
professionals such as Nurses and Physicians to play different roles. In the case of people having a CND, it is the patient who ought to be his own health care provider, then the role of the doctor or the nurse is to inform, educate and strengthen the self-management of the disease. This activity is mainly in hands of the nursing group. Such is the case of cancer, for example, since it is well known that survival is a very important stage in which self-management and family participation are essential. ${ }^{[7]}$

This has been recognized by the World Health Organization through the proposal of a care model for chronic diseases in the primary health care level, where self-management is one of the six most important activity to consider in the organization of this issues. ${ }^{[8,9]}$

The concept of self-management (SM) has been defined in various ways, for example, Barlow et al. define SM as the person's ability to manage the symptoms and consequences of living with a chronic disease; including treatment, and physical, social, and lifestyle changes. ${ }^{[10]}$ Lorig and Holman notes that even if the patients do not have chronic diseases it is impossible for them to ignore their own health; but if they do have a chronic disease, the self-management is a lifelong task. The goal of self-management is to maintain the well-being in their own psychological dimensions. ${ }^{[1]}$

For this aim, according to Corbin and Strauss, the person with a chronic disease has three tasks to do: ${ }^{[12]}$ (i) management of the medical aspects of the disease, (ii) the management of the different life roles (including the role changes caused by the disease), (iii) and the management of the psychological consequences of the chronic disease. ${ }^{[13]}$

To perform these tasks, people with chronic diseases have the following basic self-management skills: problem solving, decision making, resource use and partnership's grouping with health care providers. In addition to the tasks and basic skills, self-management is defined as family context welfare ${ }^{[14,15]}$ for being an ongoing dynamic process of self-control and self-evaluation, and for involving a change of perspective from a sick to healthy condition. Based on these concepts several programs have been developed for self-management of a chronic disease; among the most popular and which have proved its effectiveness are The Stanford Program and the Flinders University Program. ${ }^{[16]}$ The Stanford Program is a six session group program intended to let each participant to elaborate their own action plan and decision making ideas based on their own needs. The program is mainly participative and the aim is no to impose ideas. The role of the trainer is to organize the group. Unlike the individual basis Flinders University Program, the sessions in The Stanford Program are conducted on a group basis.
Based on this review of self-management definitions, this study validated the instrument used in the Flinder Australia Program in the Mexican context, which evaluates the behavior of self-management in chronic diseases. ${ }^{[17]}$

Current evidence indicates that individuals who engage in self-management behaviors improved their health. Such is the case of interventions and programs conducted by Lorig and colleagues. Lorig's approach focuses on the issues and concerns that are relevant to the individual living with that condition. ${ }^{[18]}$ Also in Mexico, we can find many studies that prove the effectiveness of educational interventions in the health indicators of people involved. ${ }^{[19,20]}$ Although the results of these studies are promising, there is little agreement about the components of the SM and the direction of future studies. Self-management is starting to be understood in terms of how it can be developed.

Self-management is a complex and multidimensional capability that can be conceptualized taking into account that it affects individuals or families. This implies that a component of a system affects others. Thus, the capacity of an individual or family will be affected in both situations: success or failure of their self-management. ${ }^{[21]}$ It is known that the characteristics of the patient can have an influence on selfmanagement. It has been identified that age, gender, income, education, social support, symptom severity and comorbidity are variables that affect self-management in patients with chronic diseases. For example, patients who live alone are less likely to seek assistance, while low-income patients are more likely to eat canned or packaged food. On the other hand, patients with a higher educational level and greater severity in their symptoms probably have more knowledge on heart failure symptoms. ${ }^{[21,22]}$

Although there is empirical evidence that SM interventions and programs improve the health of people with chronic diseases, with common tasks in SM through various conditions, there are gaps to understand the individual and family SM and to identify the results of measurements over time. This study, in its first diagnostic phase evaluates the behavior of self-management in people with three most prevalent diseases in Mexico: diabetes, hypertension and cancer, and tries to analyze a first approach of the relationship between self-management and family support.

\section{Methogology}

This study is the first phase of a bi-national project (Nursing School of Tampico, Autonomus University of Tamaulipas, Mexico, and the School of Nursing, University Cesar Vallejo, Lima-Peru), which corresponds to the diagnostic phase of self-management in people with chronic diseases (hyperten- 
sion, diabetes and cancer). The corresponding results in Mexico are shown. The study was conducted at the Sanitary District Number 2 of Tampico, Tamaulipas. From a total of 16 health centers, four were selected at random to participate in the study. In these four health centers the recruitment of patients who had a diagnosis of diabetes and hypertension was conducted and according to the inclusion criteria a total of 100 patients with diabetes and 100 patients with hypertension were selected. (Inclusion criteria: i. participants older than 18 , ii. a minimum of three months of diagnosis). One hundred participants were selected per group of illness due to financial purposes, as it was not possible to cover a higher number of participants to guarantee a minimum sample size and carry out the statistics analysis.

Patients diagnosed with cancer $(n=100)$ were selected in the area of outpatient General Hospital of the city. This is due to the lack of care programs for these types of patients in these health centers, and because of insecurity reasons within the area (violence in the streets) it was not possible to visit homes in the community. The sample consisted of 299 patients with one cancer patient being excluded due to data collection errors. Inclusion criteria were: 1) participants should be older than 18 years, 2) to have at least one of the following diseases: hypertension, diabetes and/or cancer, if one of the participants had two of the diseases, the disease that was first developed is considered, 3) had been diagnosed with at least three months. The purpose of this study is not to generalize results of a specific population, but rather to explore this population using a cross-sectional design.

Students trained in chronic care processes were involved in the implementation of the survey through their involvement with the Nursing School of Tampico. Clinical practice teachers of the school also participated by supervising the implementation of surveys. The Partners in Health (PIH) scale of self-management in chronic illness was used in the screening process to evaluate the self-management skills of participants. The PIH scale includes 12 items in four dimensions: adherence to treatment, knowledge of the disease, managing side effects and managing signs and symptoms. ${ }^{[17,18]}$ The scale was previously validated within Mexican population and it was shown to exhibit a Cronbach's alpha of 0.722 . In this work, three dimensions were identified: knowledge, adherence to treatment and symptom management; all the 12 items developed by the authors were included. ${ }^{[23]}$ The responses of the 12-item scale range from 0 to 8 points.

For the interpretation of the results a sum of all items was performed and results were standardized as grade 0 to 100 where a number closer to 0 shows poorer self-management and a number closer to 100 is seen as appropriate self-management.
Also for each dimension a sum was performed and standardized to 100 . In addition, each item was transformed into an ordinal variable using the technique of staninos; they were presented the cutoff points for the overall index and dimension in the Table 1 . To assess the perceived family support the APGAR family test was used. The questionnaire Family APGAR (Family APGAR) was designed in 1978 by Smilkstein $^{[24]}$ to explore the family functionality. The APGAR acronym refers to the five components of family function: adaptability (adaptability), cooperation (partnership), development (growth), affection (affection) and response capacity (resolution). Compared with other similar scales (CES, McMaster, FACE III, Pless-Satterwhite) it has the great advantage of its small number of items and the ease of application. This scale is validated in our setting by Bellon et al. ${ }^{[25]}$ The data analysis was carried out using the SPSS software (Statistical Package for the Social Sciences: Software release 18.0).

For the statistical analysis of continuous variables a normality test and statistical tests were performed for each objective of the study. As Kolmogorov-Smirnov normality test was decisive, the Kruskal-Wallis test was used to analyze differences between groups. The Spearman and Kendall-Tau correlation was used to analyze the relationship between self-management and family support. Each participant's informed consent was obtained. The project was reviewed by the Committee of Ethics and Research of the School of Nursing. Likewise, the research had the permission of the appropriate health jurisdiction.

\section{Results}

The average age of the study group was 55 years $(S D=13)$, with a range of 19-87 years. Seventy five point three percent of participants were female $(f=225)$ and $24.7 \%$ male $(f=$ $74)$. Ninety one percent reported receiving medical treatment at the time of implementing the survey; only 11 participants with diabetes reported not being on treatment at that time. According to age, significant differences between groups were found $\left(\chi^{2}: p=.000\right)$ where the highest percentage of diagnosed hypertension people was in the group of older adults (65 to 87 years), the higher percentage of those diagnosed with diabetes were found in the range from 19 to 64 years old $(37.2 \%)$ and cancer $(36.2 \%)$.

The results of self-management showed a mean of the general index of 84; the dimension of adherence showed a mean of 87.7 ; the dimension of symptom management had an average of 84.2, and the dimension of knowledge with an average value a 71.2 (see Table 1). When analyzed by percentage, it was observed the category of poor self-management and the following results were obtained: $17 \%$ in the overall index, 
$16 \%$ in the dimension of adherence, $14 \%$ in the dimension of symptom management and $19 \%$ in the dimension of knowledge.

Table 1. Self-management and its dimensions in diabetes, hypertension and cancer $(n=299)$

\begin{tabular}{llllll}
\hline & Mean & Median & SD & Min & Max \\
\hline General index & 84.2 & 89 & 16.6 & 11 & 100 \\
Adherence & 87.8 & 93 & 17.1 & 0 & 100 \\
Symptom & 84.9 & 92 & 20.6 & 0 & 100 \\
management & 71.2 & 75 & 29.9 & 0 & 100 \\
Knowledge & & & & &
\end{tabular}

In the comparison analysis between the overall index and dimensions between groups (according to diagnosis), the statistical significance was found in the adherence dimension (Kruskal-Wallis: $p=.000$ ), finding this difference in the group which was diagnosed with cancer vs the diabetes and hypertension groups (see Table 2). The group of people diagnosed with cancer was the one that presented the highest ranks of good adherence as compared with the groups of the other two diseases.

The results of the family APGAR showed that 7\% $(f=21)$ of the participants had severe family dysfunction, $16.7 \%$ (f $=50)$ mild dysfunction and $68.9 \%(f=206)$ good family functioning. While the APGAR does not give a diagnosis of family dysfunction it gives us a hint by measuring both the emotional environment surrounding our patients and the ability of the household to deal with the various crises. ${ }^{[24]}$

Table 2. Self-management comparison acording to disease groups (Kruskal-Wallis one-way analysis of variance)

\begin{tabular}{|c|c|c|c|c|}
\hline Self-Management & Disease & $\mathbf{n}$ & Mean Rank & $p$ \\
\hline \multirow{4}{*}{ General index } & hypertension & 100 & 140.69 & \multirow{4}{*}{.314} \\
\hline & diabetes & 100 & 150.10 & \\
\hline & cancer & 99 & 159.31 & \\
\hline & total & 299 & & \\
\hline \multirow{4}{*}{ Knowledge } & hypertension & 100 & 151.89 & \multirow{4}{*}{.578} \\
\hline & diabetes & 100 & 155.08 & \\
\hline & cancer & 99 & 142.96 & \\
\hline & total & 299 & & \\
\hline \multirow{4}{*}{ Adherence } & hypertension & 100 & 129.14 & \multirow{4}{*}{.000} \\
\hline & diabetes & 100 & 133.25 & \\
\hline & cancer & 99 & 187.99 & \\
\hline & total & 299 & & \\
\hline \multirow{4}{*}{ Symptom management } & hypertension & 100 & 140.30 & \multirow{4}{*}{.316} \\
\hline & diabetes & 100 & 151.87 & \\
\hline & cancer & 99 & 157.92 & \\
\hline & total & 299 & & \\
\hline
\end{tabular}

The results of Spearman showed a significant correlation (rs $=0.327, p=.000$ ) between the self-management and the family function in Figure 1. The analysis of the Kendall Tau correlation coefficient showed a significant correlation between self-management and family functionality (APGAR) of $0.24(p=.000)$. In Table 3 the percentages of this relationship are shown, where the group with good self-management and good family functioning represented $84 \%$ of the sample against $16 \%$ of the group with good self-management and poor family functioning.

\section{Discussion}

The results show the same trend in female patients with chronic diseases according to the reports of other Mexican studies. ${ }^{[26-28]}$ According to age, the highest percentages are found in the adult and older adult population; however, the 76 prevalence is rising in groups of younger participants. This highlights the need to strengthen prevention programs, especially the programs for diabetes and cancer which have followed the trend.

The results showed poor behaviors to properly manage their disease, with a poor overall index of $15 \%(X=66)$, similar to the percentage found in Peru. ${ }^{[29]}$ Interestingly, a better self-management will often be expected in comparison to another country where there are no educational programs for people with chronic diseases. Although these results are not comparable to other Mexican studies, because it is the first time where "The self-management in chronic illness: Partners in Health Scale" is used. Mexico has reported a poor self-care by persons with chronic diseases, especially those who have diabetes. ${ }^{[26-28,30,31]}$

ISSN 1925-4040 E-ISSN 1925-4059 


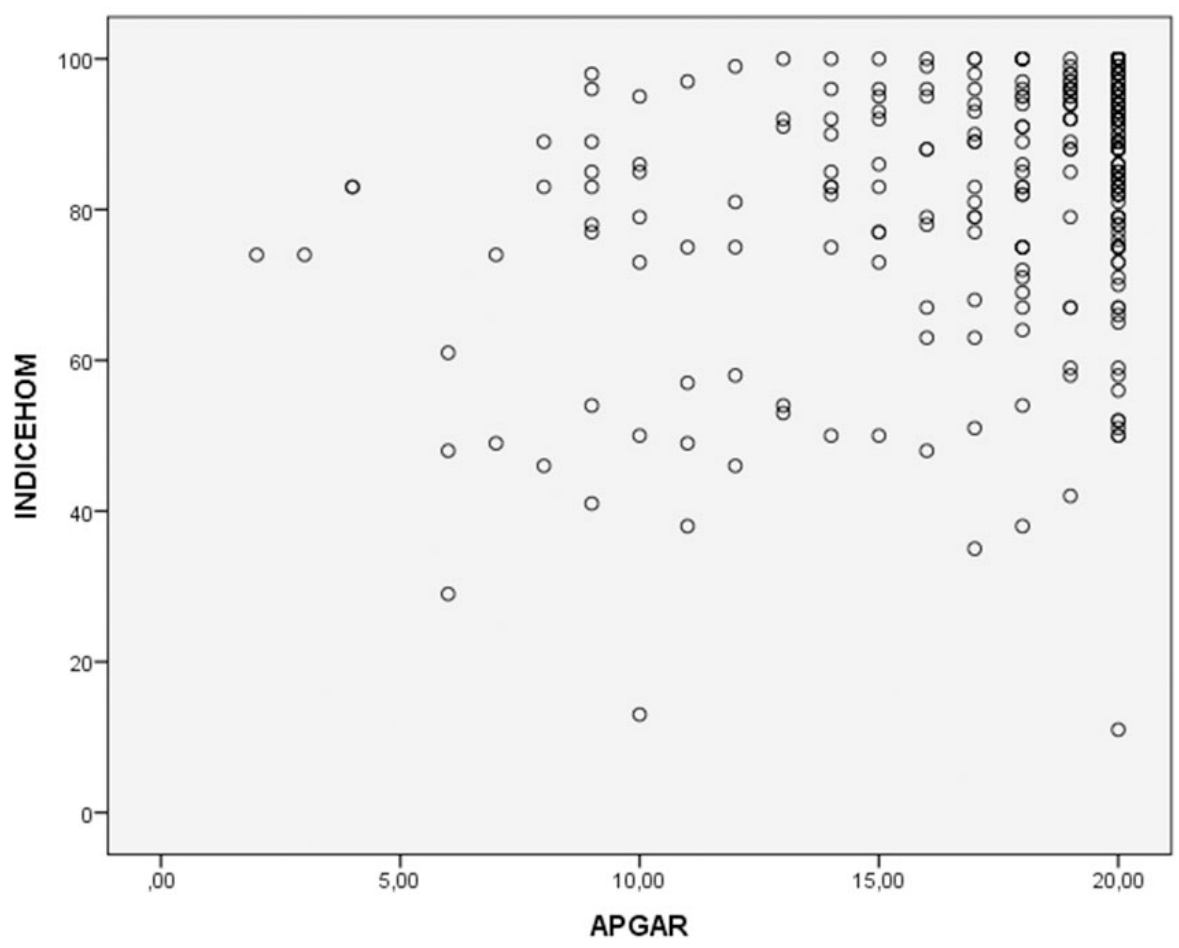

Figure 1. Correlation between self-management and family dysfunction

Table 3. Relationship between self-management and family functioning in people with chronic diseases (diabetes, hypertension and cancer)

\begin{tabular}{|c|c|c|c|c|c|c|}
\hline \multirow{3}{*}{ Apgar } & \multicolumn{6}{|c|}{ Self-management } \\
\hline & \multicolumn{2}{|c|}{ Poor } & \multicolumn{2}{|c|}{ Regular } & \multicolumn{2}{|c|}{ Good } \\
\hline & Fr & $\%$ & Fr & $\%$ & Fr & $\%$ \\
\hline Poor functionality & 25 & 49 & 57 & 31.8 & 11 & 15.9 \\
\hline Good family functioning & 26 & 51 & 122 & 68.2 & 58 & 84.1 \\
\hline Total & 51 & 100.0 & 179 & 100.0 & 69 & 100.0 \\
\hline
\end{tabular}

Note. Tau-u-Kendall: 0.215; $p=.000$

It is widely recognized the positive impact of selfmanagement/self-care in the quality of life of people who live with a chronic illness, the prevention of its complications, decreased use of health services, etc. ${ }^{[19-21,31]}$ These results should make us reflect on the need to change the way we are addressing this problem. Thus is necessary to make changes that allow us to manage properly a chronic disease.

The perspective of self-management offers us the opportunity to address this health issue differently, especially considering not only the need to empower the patient by increasing the knowledge about the disease (which has been the traditional way to face this problem), but also by adapting their "roles in life" as a result of their disease (aspects that are seen in the present study through the management of signs and symptoms) and considering the management of the psycho- logical consequences of a chronic illness. ${ }^{[13]}$ Those aspects are recognized as highly important in a self-management behavior. ${ }^{[7,30]}$

Likewise, through self-management evaluation of adherence, not only to the compliance with medical treatment which is very important and a problem in other Mexican studies, ${ }^{[27,31]}$ but also other aspects evaluated in self-management such as create partnership groups with health care providers, ${ }^{[11]}$ identify alarm signs and symptoms, and negotiate with health care providers who give their point of view. These aspects are considered important to ensure the proper self-management. According to the results of this study, those aspects are still poor. It is in this dimension where the results showed differences between the health-conditions. The group of people diagnosed with cancer showed a better adherence level. Perhaps 
this could be explained by the differences in the evolution of the disease, as people with cancer were at the post-treatment stage; that is, over 3-5 years of being diagnosed or adherence might be increased because cancer is viewed as more life threatening disease. This fact could have contributed to a better management of symptoms and moreover in this case, medical treatment is not usually self-administered. In the other dimensions and in the overall index, no differences were found between health-conditions; hence, study participants with cancer, diabetes, or hypertension, showed poor self-management.

In addition to the dimensions described above, selfmanagement is a dynamic process of self-monitoring and self-evaluation within family context. Chronic diseases threaten organic, social and emotional functions. They require long periods of hospitalization and changes personal lives of patients and their families. ${ }^{[32]}$

Adaptation to chronic disease depends on multiple factors, including social support given by family. In Latin American countries such as Mexico, we live in a patriarchal system where the premises established should be the same for men and women, where the belief system plays a key role in adapting the responsiveness of a family that must cope with a chronic disease. ${ }^{[33]}$

Although this study has not addressed the cultural aspect of the family - identifying the meaning of the disease, their perceptions of the role they play, the impact on family dynamics due to the presence of a family member living with a chronic disease, the results show that a quarter $(25 \%)$ of the study population perceived family dysfunction which may suggest that they have not achieve family adaptation to chronic illness yet.

It is important to note the similarities in the results of the researches conducted in Mexican families ${ }^{[34,35]}$ that correspond to the main features reported by other authors in psychosomatic families: stiffness, overprotection, avoidance of conflict and bonding. This dynamic causes inability to give and receive affection and to communicate. This is translated into permanent negative feelings that lead to a poor use of resources to cope and sometimes the existence of such resources is unknown. ${ }^{[36]}$

The results on the relationship between self-management and family support are corroborated by the relationship importance between both of them; ${ }^{[14,15]}$ that is, the family plays an important role in encouraging and strengthening this selfmanagement behavior in chronic disease. Studies in Mex- ico in families coping with chronic illness such as diabetes, chronic kidney disease, HIV, conclude that it is necessary to strengthen the adaptive capacity of patients and caregivers to the demands of the disease and treatment, and emotional support should be strengthened. It is confirmed that the family is the backbone of the patient. In people with diabetes, selfmanagement improves when relatives are willing to change their behavior to support the patient, when they have a similar plan and healthy eating habits, especially if combined with a high rate of patient self-efficacy. In people with HIV, family plays a role of accompaniment and emotional, financial and instrumental support. ${ }^{[36]}$

However, the results also showed that family support is not the only factor to consider in this behavior. Although the statistical results were significant, this relationship is medium or low which indicates that other factors are also influencing. Thus further research is required on these aspects; especially, to deepen on cultural aspects, differences between types of families, gender, socioeconomic aspects, as well as to use complementary instruments that measure other aspects related to family dynamics and their adaptability.

\section{Limitations of the study}

The main limitation of the study is the convenience sample which does not allow generalizing the results to similar populations. However, we believe the results are reliable because the instrument was previously validated carefully in similar populations. ${ }^{[17,29]}$ Further studies can assist in replication of data of further validate instruments used in this population.

\section{Conclusion}

- Family support plays an important role in strengthening the self-management in people with a chronic illness condition; however, its influence by itself is not enough, other factors should also be considered.

- Self-management in people with chronic conditions is still poor, especially in terms of knowledge of their disease and the management of signs and symptoms.

- It is still necessary to understand and explain more carefully self-management behavior in chronic disease to our Mexican population and its relationship with the family context, so it should be further investigated through qualitative and quantitative approaches to have a better understanding of those factors that help to reinforce this behavior and allow us to identify strategies to strengthen self-management and family involvement.

- Explore other educational strategies to increase selfmanagement skills involve families in education. 


\section{ACKNOWLEDGements}

We thank the users of health centers and the professionals who work in these centers for their great collaboration in this study.

\section{CONFLICTS OF INTEREST DisClOSURE}

The authors declare that there is no conflict of interest statement.

\section{REFERENCES}

[1] Noncommunicable Diseases Washington DC. Center for Strategic and International Studies. 2011. Available from: http: //ncdalliance.org/sites/default/files/resource_fil es/110215_Sridhar_GettingPoliticsRight_Web.pdf

[2] World Healt Organization. Preventing chronic diseases: a vital investment: World Healt Organization. 2014. Available from: http: //www.who.int/chp/chronic_disease_report

[3] Organização Mundial da Saúde. Cuidados inovadores para condições crônicas: componentes estruturais de ação Brasília: Relatório Mundial; 2003. Available from: http://www.who.int/chp/kn owledge/publications/icccportuguese.pdf

[4] Amador MB, Márquez FG, Sabido AS. Factores asociados al autocuidado de la salud en pacientes diabéticos tipo 2. Asociación Latinoamericana de Profesores de Medicina Familiar. México. 2007. 99-107. PMid:17177295

[5] Sistema Nacional de Información en Salud: búsqueda en internet. 2014. http://sinais.salud.gob.mx/basesdedatos/

[6] Organización Mundial de la Salud. Plan de Acción Mundial frente a las Enfermedades No Transmisibles. 2008. Available from: http://www.who.int/mediacentre/events/2008/wh a61/issues_paper2/es/2

[7] McCorkle R EE, Lazenby M, Dena S, et al. Self-Management: Enabling and Empowering Patients Living With Cancer as a Chronic Illnesset. Cancer J Clin. 2011; 1(61): 50-62. PMid:21205833 http: //dx.doi.org/10.3322/caac. 20093

[8] Organización Mundial de la Salud. Estadísticas sanitarias mundiales. 2014. Available from: http://www.who.int/gho/publicatio ns/world_health_statistics/ES_WHS2012_Full.pdf

[9] Bodenheimer T, Loring K, Holman H, et al. Patient self-management of chronic disease in primary care. JAMA. 2002; 19: 2469-75. http://dx.doi.org/10.1001/jama.288.19.2469

[10] Barlow J, Wrigth C, Sheasby J, et al. Self-management approachesfor people with chronic conditions: a review. Patient Educ Couns. 2002; 177-87. http://dx.doi.org/10.1016/S0738-3991(02 ) $00032-0$

[11] Lorig KR, Holman H. Self-management education: history, definition, outcomes, and mechanisms. Ann Behav Med. 2003; 17. PMid:12867348 http://dx.doi.org/10.1207/S15324796 ABM2601_01

[12] Corbin J, Strauss A. Understanding Work and Care: Managing Chronic Illness at Home. Jossey-Bass; 1989.

[13] Adams K, Greiner AC, Corrigan JM. The 1st Annual Crossing the Quality Chasm Summit - A Focus on Communities. National Academies Press; 2004. http://dx. doi .org/10.1037/e305932 005-001

[14] Dunbar SB, Clark P, Quinn C, et al. Family influences on heart failure self-care and outcomes. J Cardiovasc Nurs. 2008; 3(23): 25865. PMid: 18437068 http://dx.doi.org/10.1097/01.JCN.00 $00305093.20012 . \mathrm{b} 8$

[15] Grey M, Knafl K, McCorkle R. A framework for the study of self- and family management of chronic conditions. Nurs Outlook. 2006; 278-
86. PMid:17027605 http://dx.doi.org/10.1016/j.outlook .2006 .06 .004

[16] Lawn S, Battersby M, Harvey P, et al. A behavioural therapy approach to self-management: the Flinders Program. Diabetes Voice. 2009; 30-2.

[17] Petkov J, Harvey P, Battersby M. The internal consistency and construct validity of the partners in health scale: validation of a patient rated chronic condition self-management measure. Qual Life Res. 2010; 1079-85. PMid:20437206 http://dx.doi .org/10.1007/s 11136-010-9661-1

[18] Battersby M, Ask A, Reece M, et al. The Partners in Health scale: The development and psychometric properties of a generic assessment scale for chronic condition self-management. Australian Journal of Primary Health. 2003; 9: 41-53. http://dx. doi .org/10.1071 /PY03022

[19] Vargas SML, Rodríguez GC, Velázquez R, et al. Estudio comparativo en dos grupos de pacientes con Diabetes Mellitus tipo 2 que se someten a una intervención educativa de autocuidado en el instituto de salud del estado de México. medigraphic. 2012; 6: 10-21.

[20] Medellín-Vélez B. Desarrollo de capacidades de autocuidado en personas con diabetes mellitus tipo 2. Rev Enferm Inst Mex Seguro Soc. 2007; 91-8

[21] Ryan P, Sawin KJ. The individual and family self-management theory: background and perspectives on context, process, and outcomes. Nurs Outlook. 2009; 217-25. PMid:19631064 http://dx.doi.o $\mathrm{rg} / 10.1016 / \mathrm{j}$. outlook.2008.10.004

[22] Gardetto NJ. Self-management in heart failure: where have we been and where should we go? J Multidiscip Healthc. 2011; 4(31): 39-51. PMid:21544247 http://dx . doi .org/10.2147/JMDH . S8174

[23] Peñarrieta-de Córdova I, Flores F, Gutierrez-Gomes T, et al. Selfmanagement in chronic conditions partners in health scale instrument validation in the mexican context. Nursing management (Harrow, London, England: 1994). Nursing management. 2014; 32-7.

[24] Smilkstein G. The family APGAR: a proposal for a family function test and its use by physicians. J Fam Pract. 1978; 1231-9. PMid:660126

[25] Bellón JA, Delgado S, Luna JD, et al. Validez y fiabilidad del cuestionario de función familiar Apgar familiar. Aten Primaria. 1996; 289-96.

[26] Maya-Morales A, Hernández-Silva J, Luna-Rojas JA. Capacidades especializadas de autocuidado y adaptación de los pacientes con diabetes mellitus tipo 2. Revista conamed. 2008; 30-5.

[27] Alarcón NS, Rizo BM, Cortés E, et al. Autocuidado y adherencia terapéutica en diabetes desde una perspectiva del paciente. Waxapa; 2012

[28] Romero I, Dos Santos M, Aparecida T, et al. Autocuidado de personas con Diabetes Mellitus atendidas en un servicio de urgencia en México. Rev Latino-Am Enfermagem. 2010; 1-9.

[29] Peñarrieta M, Vergel O, Schmith L. Validación de un instrumento para evaluar el automanejo en enfermedades crónicas en el primer nivel de atención en salud. Rev Cient de Enferm. 2012; 64-73. 
[30] Peñarrieta-De Córdova M, Vergel-Camacho S, Lezama-Vigo S, et al. El automanejo de enfermedades crónicas: población de una jurisdicción de centros de salud. Rev enferm Herediana. 2013. 42-9.

[31] López-Amador KH, Ocampo-Barrio P. Creencias sobre su enfermedad, hábitos de alimentación, actividad física y tratamiento en un grupo de diabéticos mexicanos. Archivos en Medicina Familiar. 2007. 80-6.

[32] Oks H. Enfermedad crónica: un abordaje clínico que promueve el desarrollo de la voz. Sistemas Familiares. 2001; 17(3): 5-12.
[33] Rolland J. Familias, enfermedad y discapacidad: una propuesta desde la terapia sistémica. Barcelona: Gedisa. 2000.

[34] Espinosa SR. Características relacionales en familias psicosomáticas. Revista SEFPSI. 2004a; 7(1-2): 53-62.

[35] Espinosa SR. Los factores de género en la enfermedad crónica y la discapacidad. Alternativas en Psicología. 2004b; 9(10): 82-93.

[36] Vírseda JAH, Bezanilla JM. Enfermedad y familia vol. 1, Primera Edición. Universidad Autónoma del Estado de México, mayo 2014. 